 \\ doi:10.20396/revpibic2620181111
}

\section{Análise de fácies e caracterização petrofísica em depósitos do Grupo Bauru como análogos para reservatórios de hidrocarbonetos}

\section{Paola Rodrigues Rangel Rosa*, Prof. Dr. Alessandro Batezelli.}

\section{Resumo}

As geometrias, arquitetura dos corpos e variações texturais podem fornecer informações para o entendimento de características petrofísicas que podem ser usadas em estudos de análogos de reservatórios para hidrocarbonetos. $\mathrm{O}$ objetivo deste projeto é a caracterização petrofísica das fácies fluviais e eólicas da Formação Marília (Bacia Bauru) a fim de usá-las como análogos de reservatório de hidrocarbonetos. Os resultados são baseados na descrição de fácies e arquiteturas, bem como, na análise petrográfica de lâminas delgadas e técnicas de tomografia computadorizada de raios $X(C T)$, que permitiram visualizar as heterogeneidades mineralógicas e texturais presentes nas rochas de interesse.

\section{Palavras-chave: \\ Análogos de reservatórios; Petrofísica; Macrotomografia. Introdução}

O Grupo Bauru representa um dos mais importantes registros de sedimentação continental cretácea, sendo constituído de rochas lamíticas nas formações Araçatuba e Adamantina, gradando para arenitos e conglomerados nas formações Uberaba e Marília (Batezelli, 2015). Estas unidades foram interpretadas como resultado da deposição por ambientes geneticamente ligados a um sistema lacustre/aluvial de regime árido/semiárido (Batezelli, 2003; Batezelli, 2015). A Fm. Marília,tendo em vista a ocorrência de fácies eólicas, fluviais e paleossolos, constitui uma boa opção para estudos petrofísicos a fim de elaborar modelos análogos de reservatórios. Para este estudo foram usados dados de campo e laboratório, com destaque para análise de fácies, petrografia sedimentar e tomografia computadorizadas de raios $X$.

\section{Resultados e Discussão}

Foram visitados 11 afloramentos da unidade de interesse (Fm. Marilia), no estado de Minas Gerais a fim de realizar descrições de fácies, coleta de amostras e medidas de paleocorrente. As análises de fácies e da arquitetura deposicional tiveram como resultado a distinção de 3 litofácies: LF1: Depósito eólico, de alta maturidade textural, associada a arenitos finos e estratificações cruzadas acanaladas, com medidas de paleocorrente variando de oeste-noroeste para oestesudoeste, em direção a norte do trajeto; LF2: Depósito de canal e LF3: Depósito lacustre (playa lake). As análises petrográficas de arenitos e paleossolos tiveram como base a descrição de 25 lâminas visando à definição das microfácies, distribuição dos materiais detríticos e cimentação, onde se atentou para a LF1. A terceira parte do trabalho envolveu a interpretação petrofísica a fim de determinar padrões deposicionais e diagenéticos de permeabilidade e porosidade. Os dados acerca da petrofísica foram feitos a partir do pré processamento de imagens no software CoreIDRAW 2018 e segmentação pelo Jmicrovision, sendo classificados em grupos de acordo com \% de porosidade, cimentação, seleção, contato e classificação de arenito, direcionando para o tipo de ambiente associado. Foram identificados 3 microfácies: MLF1:
Quartzoarenitos a Sublitoarenitos com porosidade entre 12,5 a $32 \%$, areia muito fina a média, pobre a moderadamente selecionados, subangular, contato pontual, pouca cimentação carbonática rósea e por óxidos e algumas apresentam fragmentos vulcânicos; MLF2: Quartzoarenitos com porosidade entre 11 a 17\%, areia muito fina a fina, moderadamente selecionados, subarredondado, contato reto/longo e cimentação carbonática e em maior intensidade por óxidos de ferro. MLF3: Paleossolos muito heterogêneos com porosidade entre $1 \%$ a $40 \%$, areia muito fina a fina, moderadamente bem selecionado, arredondado, contato flutuante a pontual e cimentação por carbonato e óxidos.

\section{Conclusão}

O processo deposicional e a principalmente a cimentação das litofácies influenciaram nos dados de porosidade e permeabilidade destes arenitos eólicos, o que permitiu caracterizar sua influência na formação dos reservatórios para o desenvolvimento da exploração de óleo e gás para determinar se consiste em um análogo de reservatório de hidrocarbonetos. Enquanto em escala mesoscópica o processo de deposição eólica é homogêneo e passível de análise em estudos de afloramento, sísmica ou poços, é visível a influência de processos pós deposicionais como a cimentação por diagênese de carbonatos e óxidos que reduzem a porosidade e permeabilidade local. Para um modelo de reservatório mais realista, fatores como a heterogeneidade macroscópica, como falhas, deveriam ser analisados com base na sua influência como condutor para remobilização de fluidos.

\section{Agradecimentos}

Ao Cnpq pela bolsa de IC. Ao Projeto FAPESP 2015/17632-5 pelo financiamento da pesquisa. Ao Prof. Dr. Alessandro Batezelli pela orientação e aos colegas de pesquisa Diego Nascimento, Alexandra D. Blanco, Juan L. Osorio e Guilherme Furlan.

Batezelli, A. Análise da sedimentação cretácea no Triângulo Mineiro e sua correlação com áreas adjacentes. Tese de Doutorado, Instituto de Geociências e Ciências Exatas, Universidade Estadual Paulista, Rio Claro, 183p. 2003.

Batezelli, A. Continental systems tracts of the Brazilian Cretaceous Bauru Basin and their relationship with the tectonic and climatic evolution of South America. Basin Research, v. 2, p. n/a-n/a. 2015. 